\title{
Design and Hydrodynamic Performance of a Horizontal Axis Hydrokinetic Turbine
}

\author{
M. Nachtane ${ }^{1,2^{*}}$, M. Tarfaoui ${ }^{1,3}$, A. El Moumen ${ }^{1}$, D. Saifaoui ${ }^{2}$ and H. Benyahia ${ }^{1}$ \\ ${ }^{1}$ ENSTA Bretagne, IRDL - UMR CNRS 6027, F-29200 Brest, France \\ ${ }^{2}$ Laboratory for Renewable Energy and Dynamic Systems, FSAC - UH2C, Morocco \\ *Email: mourad.nachtane@ensta-bretagne.org
}

Phone: +33298348705

${ }^{3}$ University of Dayton, Nanomaterials Laboratory, Dayton, OH 45469-0168, United States

\begin{abstract}
Marine energy is gaining more and more interest in recent years and, in comparison to fossil energy, is very attractive due to predictable energy output, renewable and sustainable, the Horizontal Axis Hydrokinetic Turbine (HAHT) is one of the most innovative energy systems that allow transforms the kinetic energy into electricity. This work presents a new series of hydrofoil sections, named here NTSXX20, and was designed to work at different turbine functioning requirement. These hydrofoils have excellent hydrodynamic characteristics at the operating Reynolds number. The design of the turbine has been done utilising XFLR5 code and QBlade which is a Blade-Element Momentum solver with a blade design feature. Tidal current turbine has been able to capture about $50 \%$ from TSR range of 5 to 9 with maximum $\mathrm{C}_{\text {Power }}$ of $51 \%$ at TSR=6,5. The hydrodynamics performance for the CFD cases was presented and was employed to explain the complete response of the turbine.
\end{abstract}

Keywords: Marine renewable energy; horizontal axis hydrokinetic turbine; hydrofoil; hydrodynamic performance; cavitation phenomenon.

\section{NOMENCLATURE}

$\begin{array}{ll}\text { HAHT } & \text { horizontal axis hydrokinetic turbine } \\ \text { CFD } & \text { computational fluid dynamics } \\ \text { CPower } & \text { coefficient of power } \\ \text { TSR } & \text { tip speed ratio } \\ \text { TCTs } & \text { tidal current turbine } \\ \text { EMEC } & \text { european centre for marine energy } \\ \text { NACA } & \text { national advisory committee for aeronautics } \\ \text { BEM } & \text { boundary element method } \\ C_{L} & \text { coefficient of lift } \\ C_{D} & \text { coefficient of drag } \\ \text { AOA } & \text { angle of attack } \\ C_{P} \text { min } & \text { coefficient of pressure }\end{array}$




\section{INTRODUCTION}

For access to reliable, affordable, clean energy and to keep the rise in global warming to well under $2{ }^{\circ} \mathrm{C}$, innovation will be key. In this context, tidal energy is one of the more exciting emerging and innovative technology of the renewable marine energy that gives the guarantee of regular and predictable energy for commercial scale production of electrical power, Nachtane et al. [1]. According to Dajani [2], Mourad et al. [3] Horizontal axis hydrokinetic turbine was used to harness this energy to meet the rising energy request while decreasing impacting the hydrological ecology. The success of employing TCTs to exploit the tidal current is reliant on predicting their hydrodynamic performance. Methodologies require being installed for studying the physical and operational parameters of the turbines to enhance their performance. These technologies are beneficial as linked to wind turbine due to, minimal infrastructural investment, decreased environmental impacts and reduce sound problems [4-5].

In a recent survey, some researchers [6-7] had listed the companies who has started establishing tidal current turbine (TCT) farms such as Andritz Hydro Hammerfest (AHH) in Anglesey (Wales, UK), Sabella in France, GE \& Alstom Energy (France), MeyGen in Scotland, GE \& Alstom Energy, and DCNS, EDF (France\& Canada) which will start working in following years. These pre-commercial TCT projects account for the industrial solution in the future years and can be verified from the websites of these enterprises with up to date commercial news about the advancement in TCT technologies. For example, the European Marine Energy Center (EMEC) was set up with the goal to test and improve marine renewable energy systems and is functioning from 2005.

Marine current turbines have observed a lot of research work in recent years and are indeed a technology close to the industrial stage but still in the experimental phase in European Center for Marine Energy (EMEC) in Scotland or the experimental site of Paimpol in France. However, only prototypes have been tested such as two-bladed SeaGen project turbines in the UK manufactured, Three-bladed Hammerfest Strom turbine (Norway), and there multi-bladed Underwater Electric Kite (UEK) which currently work a wholly functional plant at Eagle, Alaska [8-9]. Currently, no park in the world containing many tidal turbines connected to the electricity grid. The majority of the prototypes that exist so far show that the designers of turbines have tried to rely on the technology already devoted to the wind because of the similarity, sometimes excessive, between the two concepts [10]. The global tidal energy potential is estimated at between 50 and 100 gigawatts. At the European level, the United Kingdom has 75\% of the potential, $50 \%$ in Scotland, France has $20 \%$, and the rest of the potential is divided between Greece, Italy, and Norway [11-12].

According to Li et al. [13], the hydrodynamics design method of the hydrokinetic turbine blade design can be classified into three steps (Figure 1). Various investigations have been conducted to furnish an appropriate blade section for HATCT. The principal purpose of blade conception is to improve the coefficient of lift and reduce the coefficient of drag and the coefficient of pitching moment [14]. Ahmed [15] wrote an excellent paper of the evaluation of the blade part of being utilised in TCTs. Goundar et al. [16] employed HF10XX series of blade part to design a 3-bladed HATCT rotor of $10 \mathrm{~m}$ diameter. HF present the abbreviation of the hydrofoil, new hydrofoils with various thicknesses were employed at the several parts of the blade, and the maximum power is $150 \mathrm{~kW}$ at the rated current $2 \mathrm{~m} / \mathrm{s}$, and the maximum efficiency of $47.5 \%$ was obtained. Molland et al. [17] assessed lift and drag feature and used numerical codes cavitation tunnel and experimental on NACA 6615, 63-815 and 63-215 foils, Hydrofoil who has high lift 
coefficient and high camber were get to be endangered to limited cavitation for the high coefficient of lift. Lawson and Sale [18] used NACA 63-series blade to model a HAHT rotor of $20 \mathrm{~m}$ diameter because the coefficient of pressure is big enough, who do this hydrofoil resistant to cavitation. Grasso [19] designed a two novel hydrofoil called Ghydra -A, G-hydra-B using an algorithm of Sequential quadratic programming (SQP). Batten at al. [20] employed NACA 63-8xx series to predict horizontal axis TCTs rotor characteristics and described the cavitation experiment for NACA series (63-815 and 63215).

Hydrofoils are an essential element of HAHT. To improve the turbine output and provide enough strength to the blade structure, hydrofoils must be correctly designed, Laurens et al. [21]. Moreover, in order to satisfy the requirements of TCTs designs, which are mostly, associated with problems such as mass gain, fouling resistance, corrosion resistance, manufacturing methods and coating technology according to Nachtane et al. [22], the future work will involve the use of composite materials because of their excellent mass/durability relations. This paper shows a new design of hydrofoil for Horizontal Axis Hydrokinetic Turbine. Hydrofoils were designed for various blade position; they are called as NTSXX20. The hydrodynamic performance of the hydrofoils was examined. It was guaranteed that the designed hydrofoils with delayed cavitation while the required working conditions with the low profile and the drag the high maximum lift and the insensitive to roughness have been achieved. The features of the NTSXX20 hydrofoils were linked with other frequently employed hydrofoils.

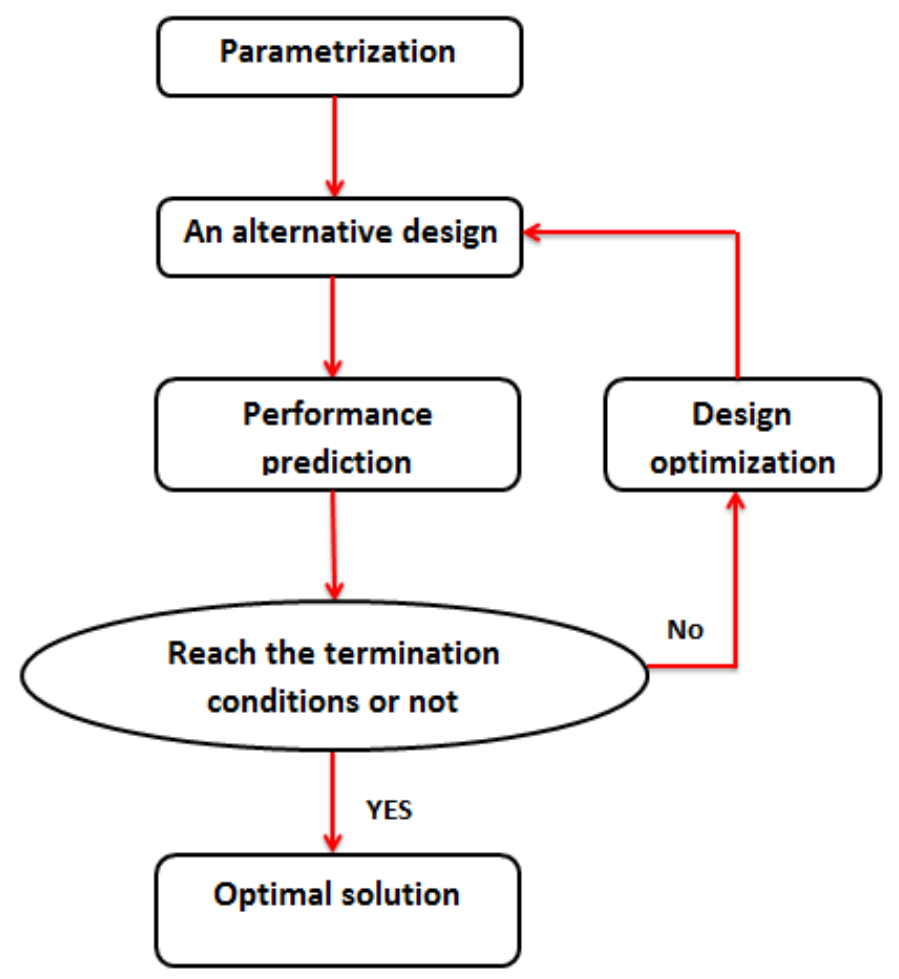

Figure 1. Blade design flowchart. 


\section{REQUIREMENT AND HYDROFOIL DESIGN CHARACTERISTICS}

The efficiency of the rotor is frequently depended on the shape of hydrofoil employed [23]. The principal objective of hydrofoil conception is to grow the coefficient of lift and reduce the coefficient of drag and the coefficient of pitching moment [24]. Cavitation phenomenon is an important element in selecting a hydrofoil for tidal current turbine blades [25]. Hydrokinetic turbine hydrofoil design can be divided into two very distinct yet interdependent domains. The first is its hydrodynamic design, while the other is its structural design. The purpose of the hydrodynamics design is to achieve a preferred external profile of the blade that provides the favourite performances, such as good blade strength, delayed stall, and cavitation-free. But the major requirements of hydrofoil design are high $C_{L}$ and high $L / D$ ratio over a wide range of AOA to obtain a good turbine performance.

On the other hand, the maximum hydrofoil thickness and the chord-wise place of the highest thickness are the most significant parameters for the optimal design of TCTs from the structural viewpoint. However, sufficient high-impact strength, corrosion resistance, and lightweight are required for tidal current turbine and can alone is performed by the use of composite materials, starting with a conception which provides a compromise among endurance, efficiency, cost, and weight [26-27-28]. The greatest dissimilarity among tidal current turbine and wind turbine blade is linked with the cavitation. This phenomenon is the formation of vapour cavities of a flowing liquid. It generally happens once a liquid is exposed to quick changes of pressure where the pressure is low enough. When exposed to higher pressure; the cavities implode and can produce an intense shock wave, [29]. It causes mechanical damage (Figure 2) to turbine blades and diminishes its performance, the coefficient of lift to reduce and coefficient of drag to increase [30-31]. The cavitation phenomenon principally depends on the pressure coefficient, the local minimum $\mathrm{C}_{\mathrm{Pmin}}$ of the blade section and the cavitation number.

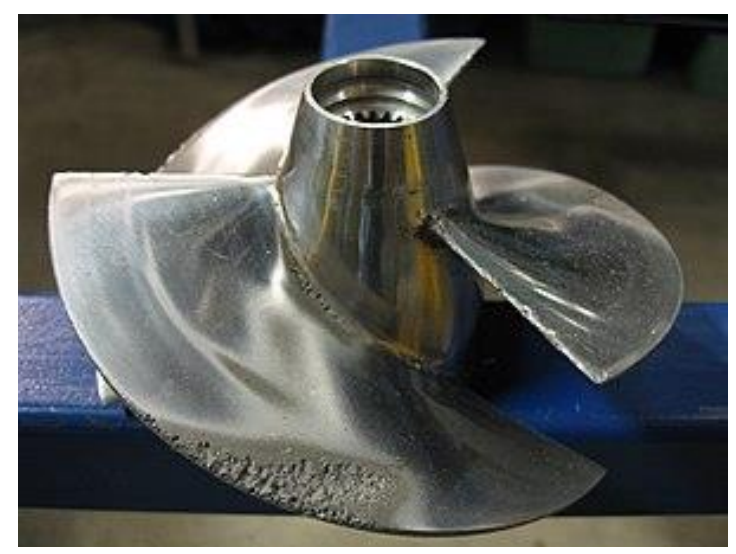

Figure 2. Structural damage due to cavitation.

A successful blade conception must meet a wide range of objectives to achieve good turbine performance:

i. maximise annual energy yield for the specified current speed distribution

ii. delayed cavitation inception

iii. resist ultimate and fatigue charges and reduce tip deflections

iv. minimise weight and cost

v. robustness to roughness 
Generally, blade element momentum theory is widely used to enhance the conception for a rotor blade and for predicting the performance with the operating requirement of the hydrokinetic, Batten et al. [32]. The performance hydrodynamic of hydrofoils on the rotating turbine work differently. Once the rotor is in motion, the blade section begins to experience a relative component of tidal current velocity at variable angles of attack depending on blade parameters. Also, the hydrofoil section experiences a different component of forces. The direction of tidal current velocity, blade forces, and angle are presented in Figure. 3. These components of forces and velocities can be utilised to predict theoretical rotor performance, employing the Blade Element Momentum (BEM) theory.

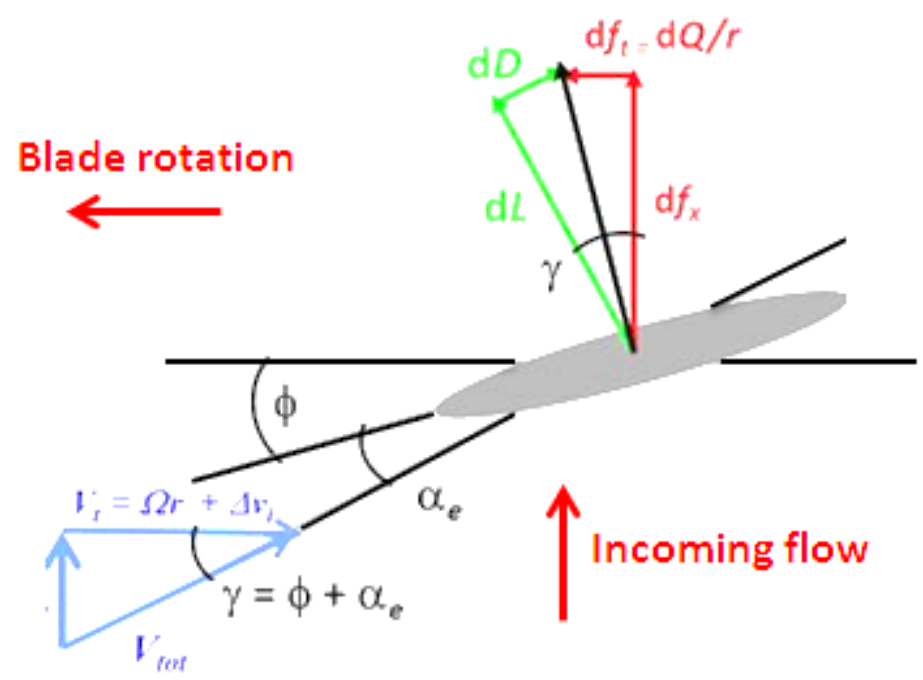

Figure 3. Hydrodynamic component of forces and velocities on horizontal axis hydrokinetic turbine.

Using BEM method by Muratoglu et al. [33], the thrust on an element of the blade due to change in the axial momentum and the torque on an element due to change in the angular momentum, comprising the Goldstein factor $\mathrm{k}$ for finite number of blades will give the equation for thrust $(\mathrm{T})$ and torque $(\mathrm{Q})$ gradient:

$$
\begin{aligned}
& \frac{\mathrm{dT}}{\mathrm{dr}}=4 \pi \rho \mathrm{r}\left[\mathrm{U}_{0}^{2} \mathrm{a}(1-\mathrm{a}) \mathrm{k}+(\mathrm{a} \Omega \mathrm{rk})^{2}\right] \\
& \frac{\mathrm{dQ}}{\mathrm{dr}}=4 \pi \rho \mathrm{r}^{3} \mathrm{a}^{\prime} \Omega \mathrm{U}_{0}(1-\mathrm{a}) \mathrm{k}
\end{aligned}
$$

By considering the blade element, the local lift and drag gradient can be defined by:

$$
\begin{aligned}
& \frac{\mathrm{dL}}{\mathrm{dr}}=\frac{1}{2} \rho \mathrm{NW}^{2} \mathrm{C}_{\mathrm{L}} \\
& \frac{\mathrm{dD}}{\mathrm{dr}}=\frac{1}{2} \rho \mathrm{cNW}^{2} \mathrm{C}_{\mathrm{D}}
\end{aligned}
$$


Where $\mathrm{N}$ is the number of blades, the rotor thrust, and torque can now be defined as:

$$
\begin{aligned}
& \frac{\mathrm{dT}}{\mathrm{dr}}=\frac{\mathrm{dL}}{\mathrm{dr}} \cos \varphi+\frac{\mathrm{dD}}{\mathrm{dr}} \sin \varphi \\
& \frac{\mathrm{dQ}}{\mathrm{dr}}=\mathrm{r}\left(\frac{\mathrm{dD}}{\mathrm{dr}} \cos \varphi+\frac{\mathrm{dL}}{\mathrm{dr}} \sin \varphi\right)
\end{aligned}
$$

Combining Eq. (1), (2), (5) and, (6) yields equations for axial (a) and tangential ( $\left.a^{\prime}\right)$ inflow factors, these can be solved by iterating $\varphi$.

$$
\begin{aligned}
\frac{\mathrm{a}}{1-\mathrm{a}} & =\frac{\sigma \mathrm{k}}{4 \pi \mathrm{k} X_{\mathrm{r}} \sin ^{2} \varphi}\left[\mathrm{C}_{\mathrm{x}}-\frac{\sigma_{\mathrm{k}} \mathrm{C}_{\mathrm{y}}}{4 \pi \mathrm{k} \mathrm{X}_{\mathrm{r}} \sin ^{2} \varphi}\right] \\
\frac{\mathrm{a}}{1+\mathrm{a}}, & =\frac{\sigma_{\mathrm{k}} \mathrm{C}_{\mathrm{y}}}{4 \pi \mathrm{k} \mathrm{X}_{\mathrm{r}} \sin \varphi \cos \varphi}
\end{aligned}
$$

Where $C_{x}=C_{L} \cos \varphi+C_{D} \sin \varphi, C_{y}=C_{L} \sin \varphi-C_{D} \cos \varphi$, and the final equation for power and thrust gradient are given by Eq. (9) and (10), the integration of these equations gives power and thrust.

$$
\begin{aligned}
\frac{d C_{P}}{d x} & =\frac{2 \operatorname{TSR}(1-a)^{2} \sigma_{k} C_{y} X}{\pi \sin ^{2} \varphi} \\
\frac{d C_{T}}{d x} & =\frac{2(1-a)^{2} \sigma_{k} C_{X}}{\pi \sin ^{2} \varphi}
\end{aligned}
$$

\section{HYDRODYNAMIC PERFORMANCE OF A HYDROKINETIC TURBINES BLADE}

Hydrofoils are essential element of horizontal axis hydrokinetic turbine that helps to transform kinetic energy into mechanical energy and their excellent design engage to the increased overall performance of the blade [33]. Usually, there is no existing hydrofoil, which satisfies all conditions, or manufacturer thinks, that he can conception something novel with enhanced performance. Beginning from this point, each manufacturer has its proper approach and his approved tools to proceed. Several methodologies can be adopted, some like to employ an inverse design technique (like the Eppler code) suggested by Lighthill and commonly promoted by Eppler to ordain flow parameters and obtain the resulting shape (hydrofoil) from the code by iteratively changing the pressure repartition on the hydrofoil surface, Selig et al. [34]. Others prefer to employ a starting hydrofoil and employ analysis codes (or a wind tunnel) to proceed in a trial and error style to obtain an excellent hydrofoil shape.

In general, this second approach is usually employed in combination with a numerical optimisation code. A review of research literature in tidal current turbine design shows that the Computational fluid dynamic is commonly utilised software for the performance study of a hydrofoil [13]. A wide variety of numerical methods used in wind power are applied in the tidal field. However, the difference in operation in air and water implies that air calculation methods have limitations in representing the physics of the 
flow around the blades of a tidal turbine. Additionally, RFOIL and Xfoil are the frequently employed codes for a 2D model who can afford coefficient of lift $\left(\mathrm{C}_{\mathrm{L}}\right)$, the coefficient of drag $\left(\mathrm{C}_{\mathrm{D}}\right)$, and coefficient of pressure $(\mathrm{CP})$ of the hydrofoil. When the required factors are suitably set, same Reynolds number and boundary layer, Xfoil, RFOIL and XFLR5 can also be utilised for analysis and conception design hydrofoil. Among benefits, according to Marten et al. [35] XFOIL code is greatly more efficacy than computational fluid dynamic tools because it's free from mesh structure which often drives to a huge time of simulation. It is affirmed to be appropriate for foretelling cavitation criteria at the introductory conception step. When the AOA is little, XFOIL code can foretell the efficiency of the hydrofoil such as computational fluid dynamics tools do, but it missed after stall. You have to use the Viterna method to spend the available range of XFOIL from pre stall to post-stall.

In this research, a high lift hydrofoil suited for low Reynolds number regime and a high lift ability similar WORTMANN (FX74-CL5-140) is selected into account for design and analysis of a new hydrofoil by changing its shape. In order to improve their hydrodynamic characteristics and to make it operates at the requirement for hydrokinetic turbines, Hydrofoil redesigned by interacting changing of geometrical parameters such as ( highpoint position, LE radius, Max thickness and camber, camber line via geometry specification, TE thickness, flap deflection, camber line via loading change specification, explicit contour geometry) by employing computational analysis. Experimental analyses of hydrofoil via wind tunnel tests are rather hard to conduct due to the expensive cost of the wind tunnel. In this context, various numerical investigations codes were established providing technical support for the foil study XFLR5 [35], RFOIL [18], XFOIL [29]. In this research, XFLR5 code was used which comprise the program for foil analysis with viscous boundary layer and wake model by employing traditional methods at low Reynolds numbers. The results of the performance of the designed model have been linked with some experimental data found in the open literature and the results of other simulations. The curve for the check of XFLR5 performance relative to the numerical and experimental results is presented in Figures 4 and 5. XFLR5 code presents great performance correlating with experimental results [36] and numerical investigation software.

The FX 74-CL5-140 airfoil was utilized as the reference for the optimization by modifying their maximum camber, maximum thickness, nose radius to enhance their hydrodynamic performance. The optimized hydrofoil was greatest to operate as a hydrofoil for hydrokinetic turbines, with the growth in the chamber by $10 \%$ and thickness by $20 \%$. It is named as NTSXX20 and the profile can be viewed in Figure 6 .

To achieve low drag, an ideal weight slope is satisfactory along the upper surface to around 30-percent chord. Toward the back of this point, a short locale of troublesome pressure gradient ("Transition ramps") is invaluable to upgrade the productive change from laminar to turbulent stream. Along these lines, the underlying incline of the pressure recovery is moderately shallow. This short area is kept by firm concave pressure recuperation. The particular concave pressure recuperation connected portrays a tradeoff among high lift, low drag, and accommodating slow down attributes. The precarious unfriendly pressure angle on the upper surface toward the back of around 90-percent chord is a 'separation ramps' initially proposed by F. X. Wortmann, which limits turbulent division to a little locale close to the trailing edge [37]. By controlling the development of the division point at high approaches, high lift coefficient can be accomplished with little drag punishment. This element has the additional advantage that it too advances quiet slow down qualities. 


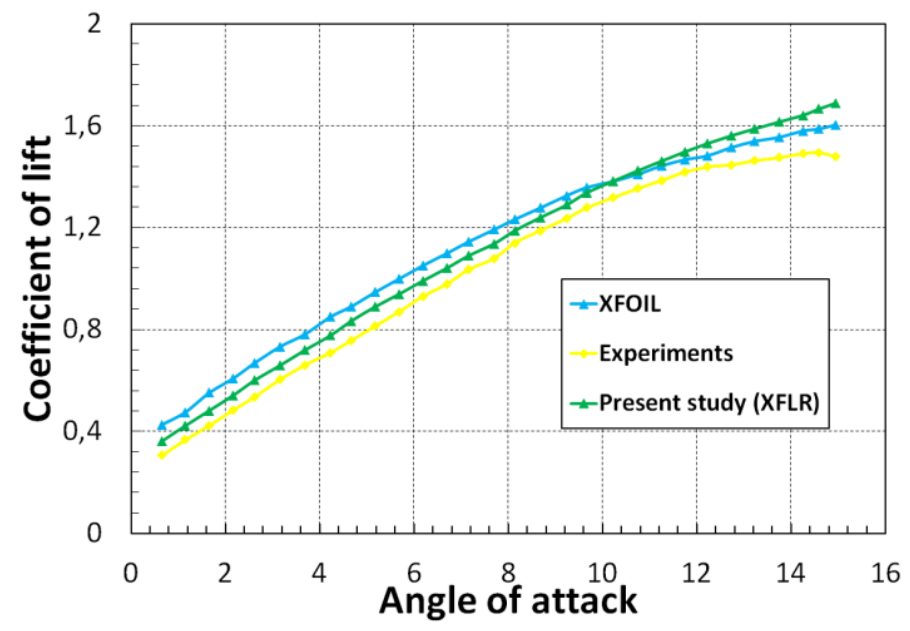

Figure 4. Validation of XFLR code with numerical and experimental results for the NACA-633418 airfoil. $\operatorname{Re}=10^{6}$, free.

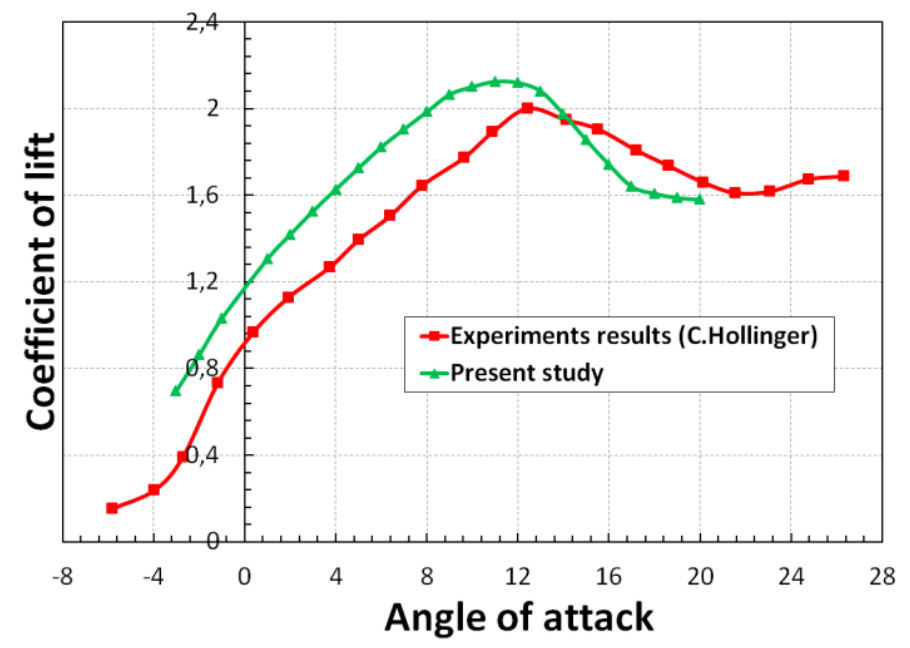

Figure 5. Numerical and experimental of the coefficient of lift of FX 74-CL5-140 at $\operatorname{Re}=106$.

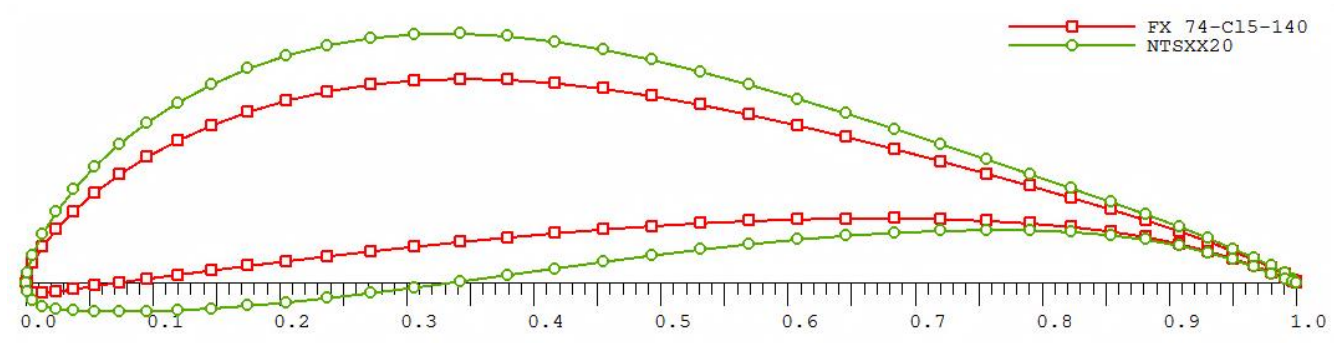

Figure 6. Hydrofoil NTESXX20 modified from FX74-CL5-140.

For more illustration, the pressure coefficient designed around hydrofoil is presented in Figure 7 for the AOA $13^{\circ}$. The pressure built in the top surface for both hydrofoils diminishes quickly from leading to trailing edge, but in the inferior side, it grows. With the growing of relative thickness, the coefficient of pressure reduces more gently in the upper surface but grows quickly in the lower surface. Pressure variance 
grows with growing hydrofoil thickness once linked superior and inferior surfaces. Though with the growing relative thickness, the coefficient of drag also rises, and the coefficient of lift growth is not proportionate to the thickness of hydrofoil. If the coefficient of drag didn't grow with the thickness of hydrofoil, thick hydrofoil would have a greater coefficient of lift.

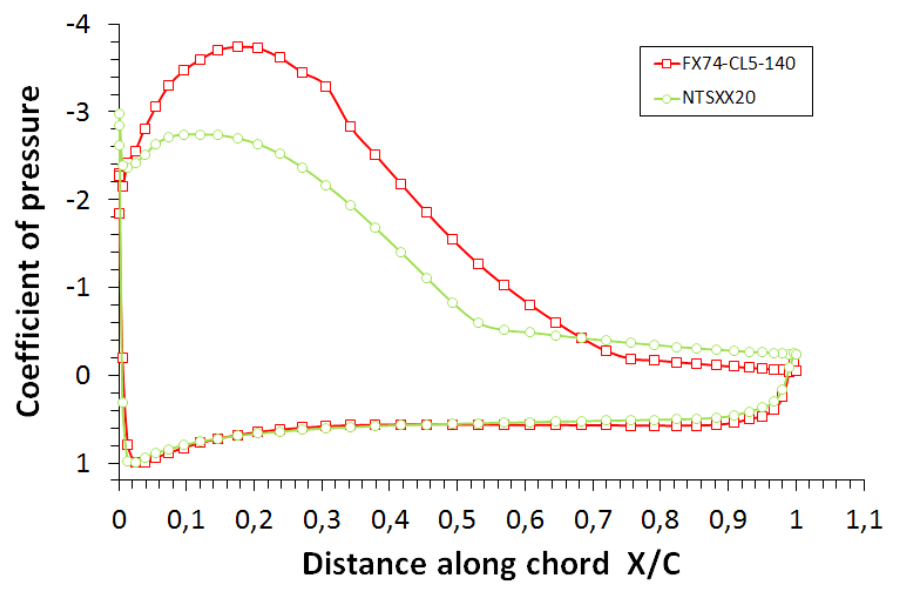

Figure 7. Pressure coefficient distribution of NTESXX20 and FX74-CL5-140 at $\alpha=$ $13^{\circ}$ and $\operatorname{Re}=2 \cdot 10^{6}$.

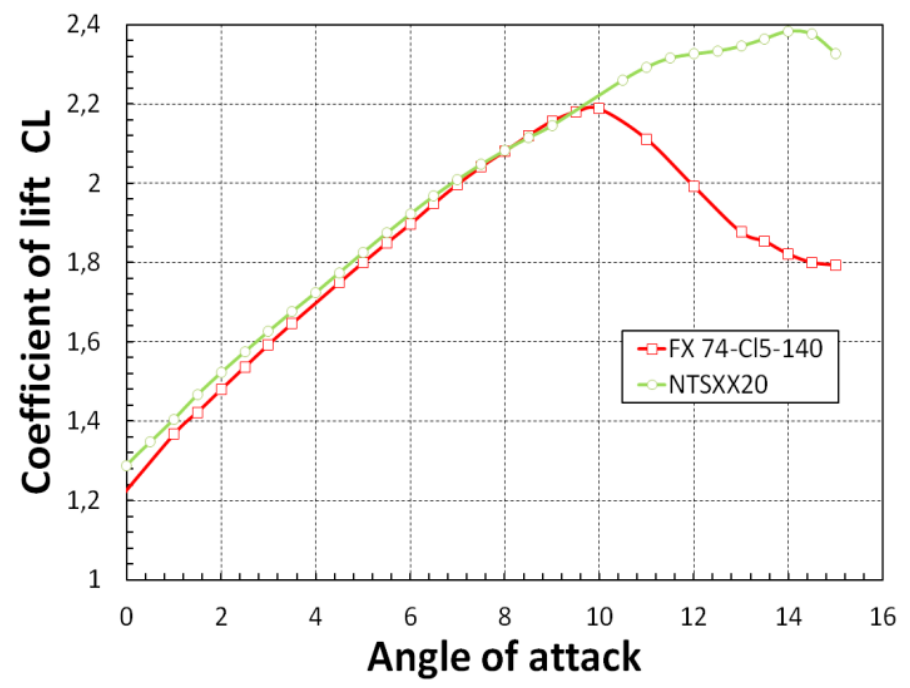

Figure 8. Variation of the coefficient of lift for NTSXX20 compared with FX74-CL5140 at different $\mathrm{AOA}$ and $\mathrm{Re}=2 \cdot 10^{6}$.

Growing the camber and maximum thickness of hydrofoil growths its minimum coefficient of pressure $C_{\text {Pmin }}$, can be viewed in Figure 7, minimum $C_{P \min }$ of FX74-CL5140 at $13^{\circ}$ angle of attack $(\alpha)$ is about $-3,9$ and for NTSXX20 it has augmented to about -3 . This will restrict the cavitation; despite the missing zone in growing the force pressure is augmented as the $C_{\text {pmin }}$ among lowest $C_{P m i n}$ and the transition region rises, later grew $\mathrm{C}_{\mathrm{L}}$ and decreased $\mathrm{C}_{\mathrm{D}}$ of the hydrofoil can be observed in Figure 7 and 8. NTSXX20 has a greater $C_{L}$ and lower $C_{D}$ related to FX74-CL5-140, it also has a higher thickness linked to FX74-CL5-140 granting more strength and durability to the blade structure, as in Figure 9. 


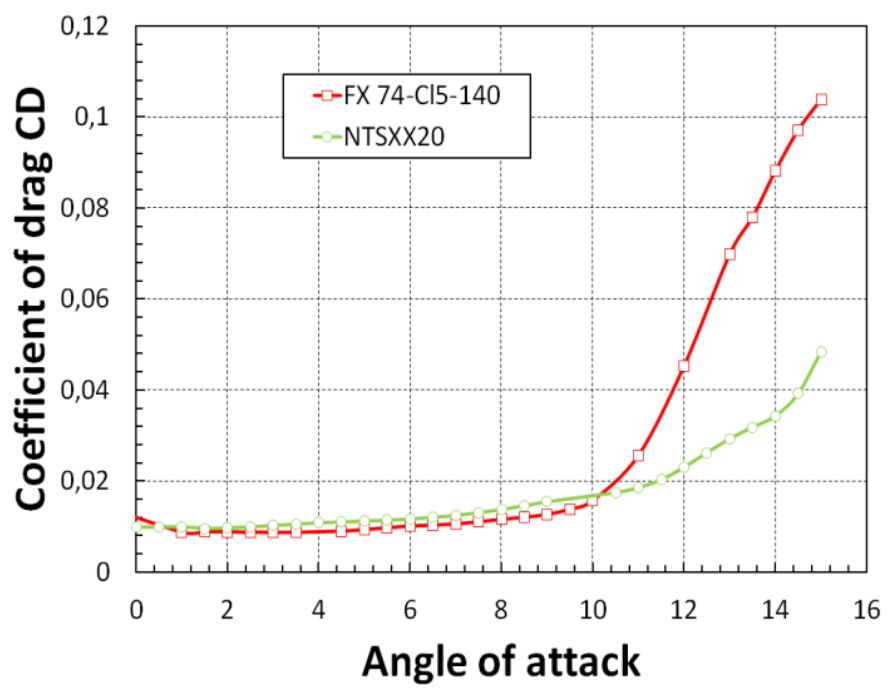

Figure 9. Variation of the coefficient of drag for NTSXX20 compared with FX74-CL5140 at different $\mathrm{AOA}$ and $\mathrm{Re}=2.10^{6}$.

QBlade's BEM code was employed to simulate the turbine performance curve of the HAHT under the operating condition with an incoming water speed of $2 \mathrm{~m} / \mathrm{s}$ over a TSR range from 1 to 10 (See figure 10). The XFLR function of QBlade was employed to gather the lift and drag data for each hydrofoil sections and the $360^{\circ}$ polar Montogomerie extrapolated method is employed. Data from XFLR was loaded in the BEM function of Qblade utilizing the resulting design of the HAHT. Figure 11 shows the resulting HATT performance curve maintained a $C_{\text {power }}$ value of over $50 \%$ from TSR range of 5 to 9 with maximum $\mathrm{C}_{\text {Power }}$ of $47 \%$ at $\mathrm{TSR}=6,5$.

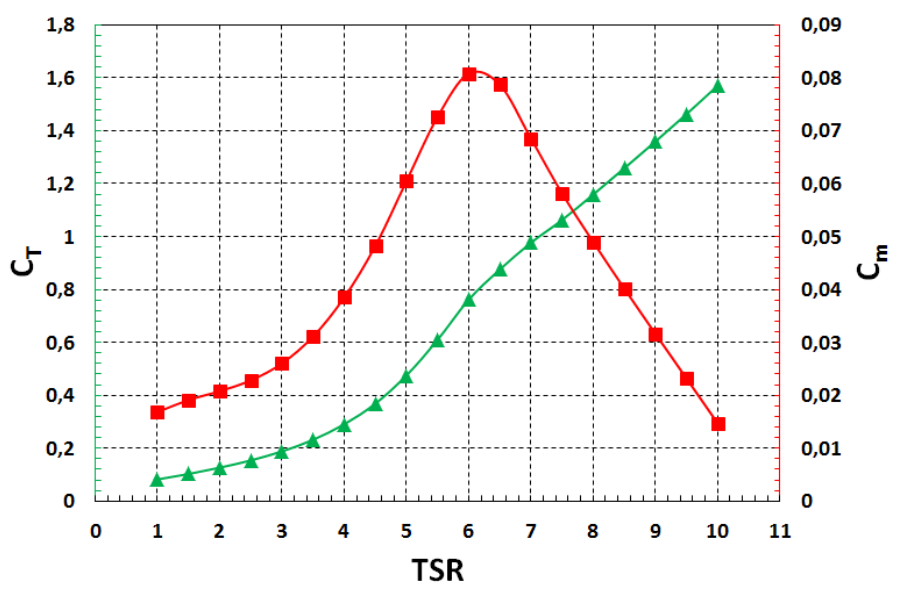

Figure 10. Hydrodynamic performance curve from the QBlade BEM results. 


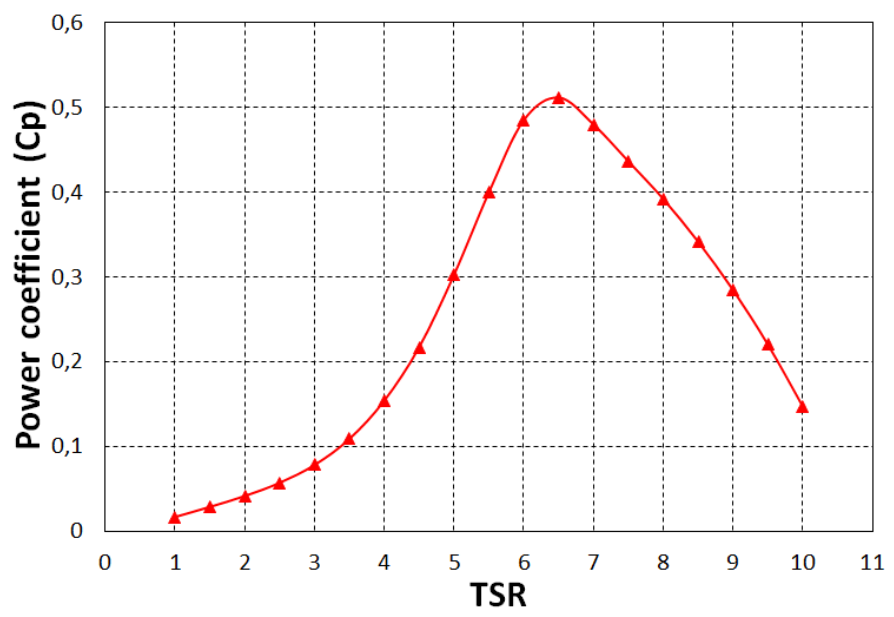

Figure 11. $\mathrm{C}_{\text {power }}$ vs TSR curve from the QBlade BEM results.

\section{CFD SIMULATION OF HYDROFOILS}

The CFD simulations of new hydrofoil were conducted in the Abaqus, as 2D models. The simulations provided for studying pressure and velocity distribution as well as the lift and drag forces. Figure 12 shows the velocity and pressure distribution for the angle of attack $\alpha=0^{\circ}$. The key factor for extracting energy is a hydrofoil and its hydrodynamic performance. For the evaluation of this factor, tools using BEM (blade element theory) like XFLER can be employed. However, much more information can be gained from CFD simulations, which employ numerical solutions of flow governing equations. These are continuity equation which is also called mass conservation equation and Navier Stokes equation [38]:

$$
\frac{\partial \rho}{\partial \mathrm{t}}+\nabla \cdot(\rho \mathrm{U})=\mathrm{S}_{\mathrm{M}}
$$

The final equation defined by:

$$
\frac{\partial(\rho \mathrm{h})}{\partial \mathrm{t}}-\frac{\partial \rho}{\partial \mathrm{t}}+\nabla \cdot(\rho \mathrm{Uh})=\nabla \cdot(\lambda \nabla \mathrm{T})+\nabla(\mathrm{U} \tau)+\mathrm{U} \cdot \mathrm{F}+\mathrm{S}_{\mathrm{E}}
$$

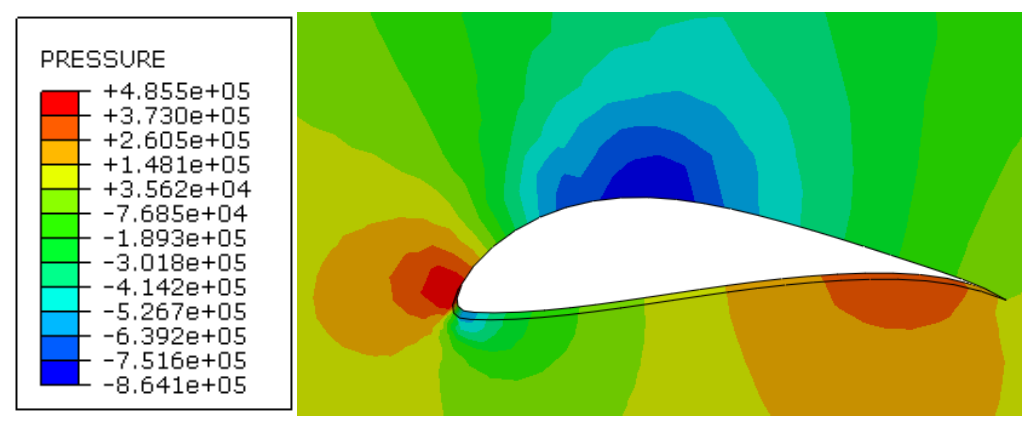

(a) $1 \mathrm{~m} / \mathrm{s}$ 

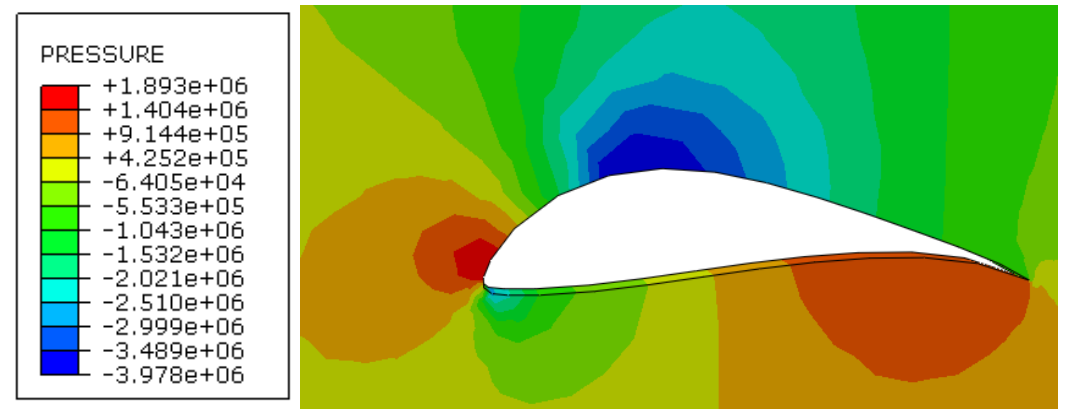

(b) $2 \mathrm{~m} / \mathrm{s}$
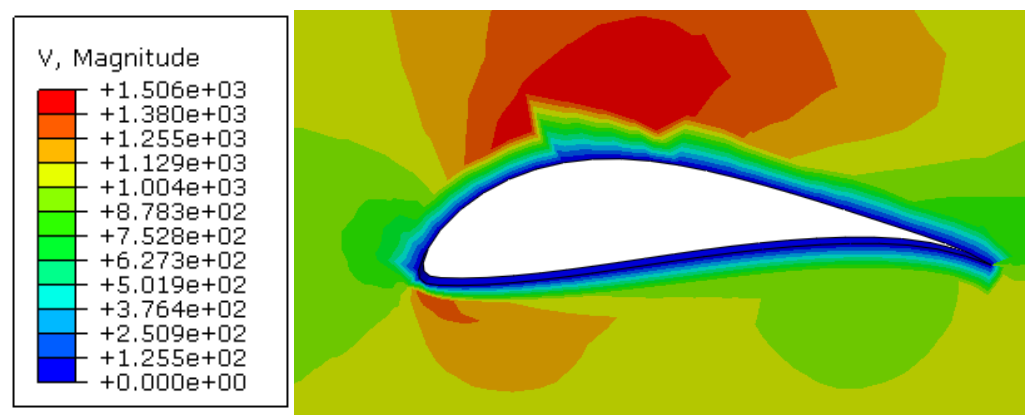

(c) $1 \mathrm{~m} / \mathrm{s}$
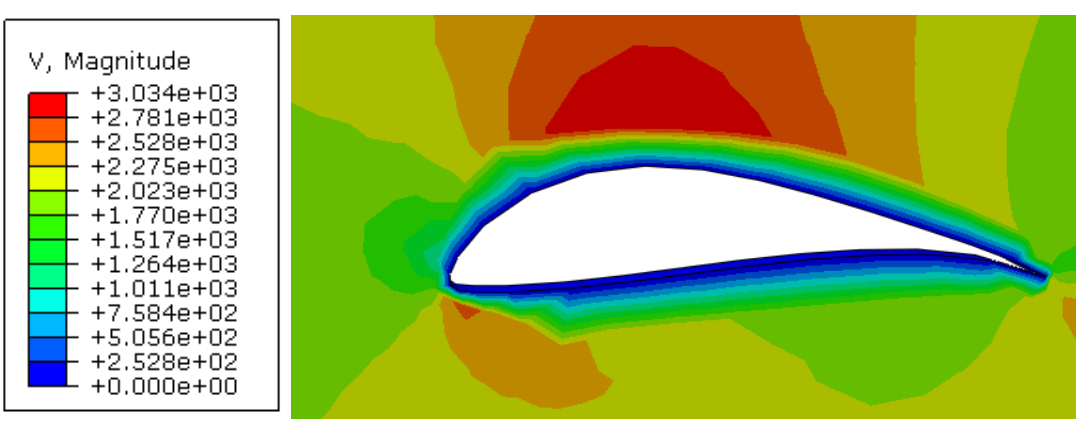

(d) $2 \mathrm{~m} / \mathrm{s}$

Figure 12. (a), (b) Pressure and (c), (d) velocity distribution of NTSXX20.

\section{HYDRODYNAMIC CHARACTERISTICS OF THE NTSXX20 COMPARED WITH OTHER HYDROFOIL DESIGN}

The hydrodynamic features of various hydrofoils were analysed at $\operatorname{Re}=2.10^{6}$ [20]. Figure 13 shows the comparison between the designed hydrofoil for this study and other hydrofoils. The coefficient of pressure for various hydrofoils at different AOA can be observed in Figure 14. The $C_{L}$ and $C_{D}$ variations for various hydrofoils at various AOA can be viewed in Figures 15 and 16. It presents that the AOA for maximum $\mathrm{C}_{\mathrm{L}}$ for other hydrofoils is among $15^{\circ}$ and $18^{\circ}$ except for NTSXX20 is among $12^{\circ}$ and $15^{\circ}$. Therefore, the Lift to drag ratio gets very little at these AOA, as can be viewed from Figure 17. 


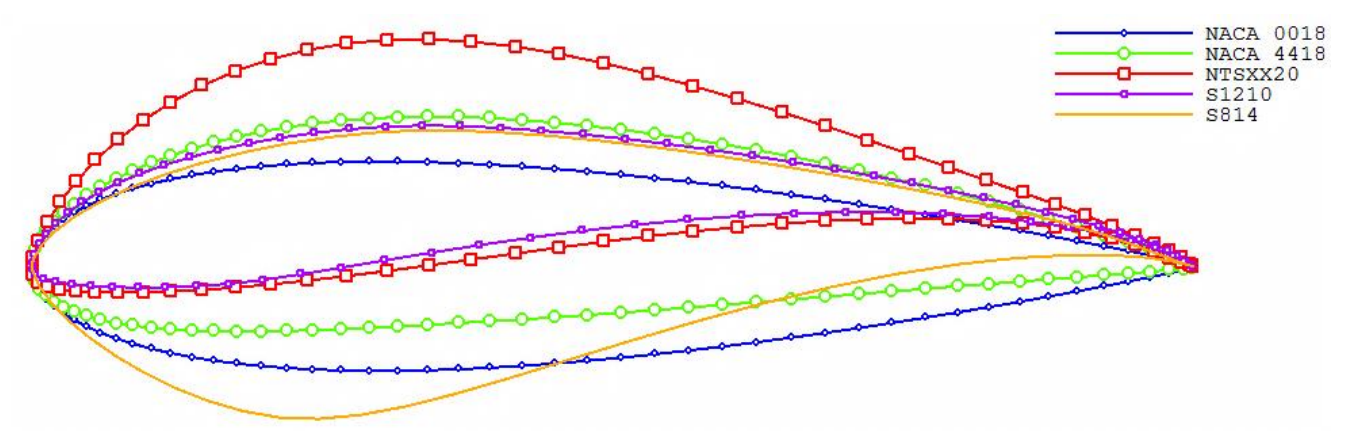

Figure 13. NTESXX20 hydrofoil profile compared with different hydrofoil.

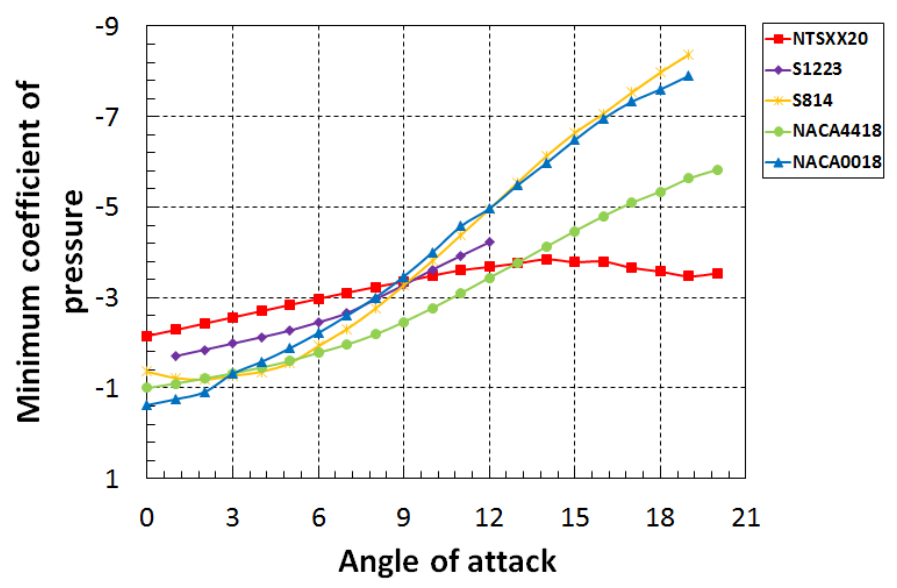

Figure 14. coefficient of pressure for various hydrofoils, at various AOA

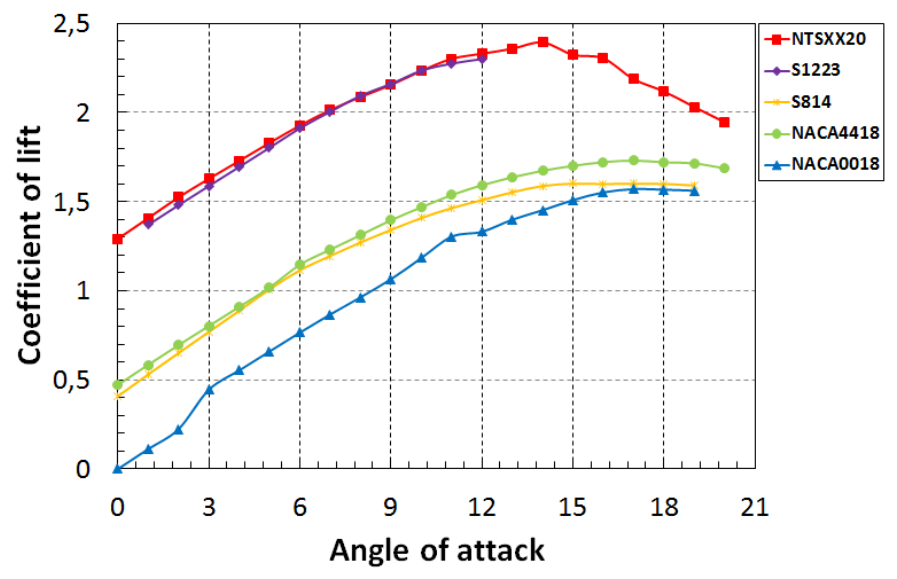

Figure 15. The coefficient of lift for various hydrofoils, at various AOA.

The hydrofoil NACA 4418 has been numerically analysed for Horizontal of axis marine current turbine in [39]. It has the maximum coefficient of lift at around angle of attack of $17^{\circ}$, around 1.70 and coefficient of drag of about 0.048 , (see Figures 13,14). Minimum $\mathrm{C}_{\mathrm{Pmin}}$ at maximum $\mathrm{C}_{\mathrm{L}}$ is about -5.098 . There will be luck of cavitation phenomena on the blade if the maximum $\mathrm{C}_{\mathrm{L}}$ is being used for greater performance. NACA 0018 airfoil has been utilised as a blade part for TCTs in [40]. It has the maximum $\mathrm{C}_{\mathrm{L}}$ at about $\mathrm{AOA}$ of $18^{\circ}$, around 1.570 and drag of about 0.036 , at maximum $\mathrm{C}_{\mathrm{L}}$, the minimum $\mathrm{C}_{\text {Pmin }}$ is about -7.33 ; however, its lift to drag ratio (L/D) get very little that is not proper 
for conception a great performance rotor. S814 profile has been employed as a hydrofoil section for hydrokinetic turbines in [41-42]. It has a higher $C_{L}$ around 1.60 between $15^{\circ}$ $17^{\circ}$ AOA but it has very little lift to drag ratio of a smaller amount of than 20 and minimum $\mathrm{C}_{\mathrm{Pmin}}$ of $-7.53^{\circ}$. S1223 profile has been utilised as the hydrofoil section for the hydrokinetic turbine in [43]. It has greater $\mathrm{C}_{\mathrm{L}}$ around 2.30 at $12^{\circ} \mathrm{AOA}$ and L/D ratio about 149.22 and minimum $\mathrm{C}_{\mathrm{Pmin}}$ of $-4.22^{\circ}$. However, the NTSXX 20 has a considerably higher lift of about 2.2 at $11^{\circ}$ angle of attack and greater Lift to Drag ratio of about 80 and lowest $\mathrm{C}_{\mathrm{Pmin}}$ of -3.6 , suitable for a great-performance rotor with delayed cavitation.

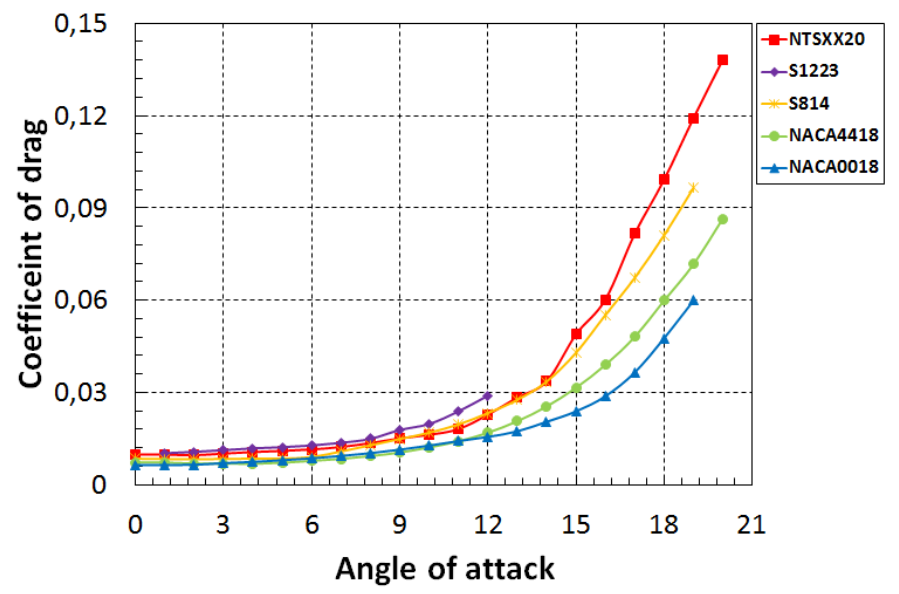

Figure 16. The coefficient of drag for various hydrofoils, at various AOA.

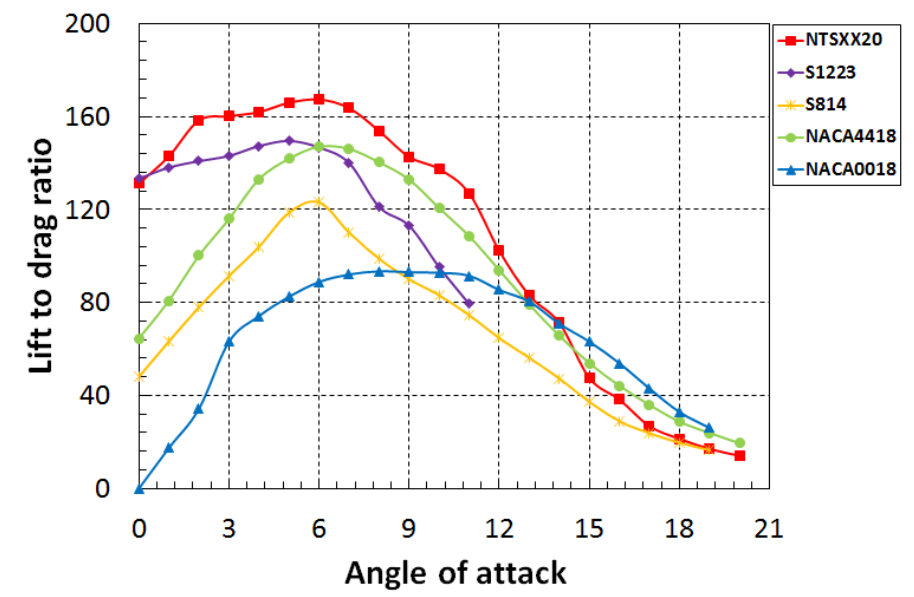

Figure 17. Lift to drag ratio for various hydrofoils, at various AOA.

\section{CONCLUSION}

To maximise the turbine output and afford enough strength to the blade structure, hydrofoils must be carefully designed. This research concentrated on the design of a new hydrofoil for the hydrokinetic turbine. The specifications for design hydrokinetic hydrofoil are illustrated. The blade section of the rotor is one of the indispensable parts of the hydrokinetic turbine which can convert kinetic energy the current into rotational energy to produce electricity. The hydrodynamic performance of a new hydrofoil is calculated using Qblade solver. As wind Tunnel Test is costly and not available everywhere, XFLR5 can be an excellent tool to analyse and discover out better-suited 
hydrofoil for a hydrokinetic turbine as per the exigency. In addition, new hydrofoil can be designed and examined according to the requirement at a low price. Despite these good results, in the future work wind tunnel tests are suggested to endorse predictions, particularly for the stall performance.

\section{REFERENCES}

[1] Nachtane M, Tarfaoui M, El Moumen A, Saifaoui D. Damage prediction of horizontal axis marine current turbines under hydrodynamic, hydrostatic and impacts loads. Composite Structures. 2017; 170:146-157.

[2] S. Dajani M, Shehadeh N, Hart D, Cheshire. Aspects of Tidal Power Resources in Egypt, International conference on Recent Advances in Energy Systems (RAEPS-12), Alexandria, Egypt, 2012.

[3] Mourad N, Mostapha T, Dennoun S. Promotion of renewable marine energies in Morocco: Perspectives and strategies. World Acad. Sci. Eng. Technol. Int. J. Energy Power Eng, 2018.

[4] Mohammed MA. . Etude des tuyères composites pour une conception optimale d'une hydrolienne à axe horizontal (Doctoral dissertation, Université de Bretagne occidentale-Brest). 2017.

[5] Nachtane, M, Tarfaoui, M, Hilmi K, Saifaoui D, El Moumen A . Assessment of Energy Production Potential from Tidal Stream Currents in Morocco. Energies.2018; 11: 1-18.

[6] Zhou, Z., Benbouzid, M., Charpentier, J. F., Scuiller, F., \& Tang, T. Developments in large marine current turbine technologies-A review. Renewable and Sustainable Energy Reviews. 2017; 71:852-858.

[7] Nachtane, M., Tarfaoui, M., \& Saifaoui, D. Matériaux composites pour les énergies marines renouvelables. Éditions universitaires européennes.2017

[8] Røkke A, Nilssen R. Marine Current Turbines and Generator preference. A technology review, International Conference on Renewable Energies and Power Quality (ICREPQ'13) Bilbao (Spain), 2013

[9] Pelc R, Fujita RM. Renewable energy from the ocean. Marine Policy. 2002; 26(6):471-479.

[10] Douglas CA, Harrison GP, Chick JP. Life cycle assessment of the Seagen marine current turbine. Proceedings of the Institution of Mechanical Engineers.2008; 222: 1-12.

[11] Sleiti AK. . Tidal power technology review with potential applications in Gulf Stream. Renewable and Sustainable Energy Reviews. 2017; 69: 435-441.

[12] Schiermeier Q, Tollefson J, Scully T, Witze A, Morton O. Energy alternatives: Electricity without carbon. Nature News. 2008; 454(7206): 816-823.

[13] Li W, Zhou H, Liu H, Lin Y, Xu Q. Review on the blade design technologies of tidal current turbine. Renewable and Sustainable Energy Reviews. 2016; 63: 414422.

[14] Colby J. Multi-scale Hydrodynamic analysis of kinetic hydropower arrays. Nortek USA Technical Symposium ,2011.

[15] Ahmed MR "Blade sections for different turbine and tidal current turbine applications-current status and future challenges," International Journal of Energy Research.2012; 36(7): 829-844.

[16] Goundar JN, Ahmed MR. Design of a horizontal axis tidal current turbine. Applied energy, 2013;111:161-174. 
[17] Molland AF, Bahaj AS, Chaplin JR, Batten WMJ. Measurement and predictions of forces, pressures and cavitation on 2-D sections suitable for marine current turbines, in Proceedings of the Institution of Mechanical Engineers, Part M: Journal of Engineering for the Maritime Environment, 2008.

[18] Lawson MJ, Li Y, Sale DC. Development and verification of a computational fluid dynamics model of a horizontal-axis tidal current turbine, in ASME 30th International Conference on Ocean, Offshore and Arctic Engineering, Rotterdam, 2011.

[19] Grasso F. Design and optimization of tidal turbine airfoil, Journal of Aircraft, 2012;49(2): 636-643,

[20] W. M. J. Batten, A. S. Bahaj, A. F. Molland and J. R. Chaplin, The prediction of hydrodynamic performance of marine current turbines, Renewable Energy, 2008;33(5): 1085-1096.

[21] Laurens JM, Ait-Mohammed M, Tarfaoui M. Design of bare and ducted axial marine current turbines. Renewable Energy, 2016; 89:181-187.

[22] Nachtane M, Tarfaoui M, Saifaoui D, El Moumen A, Hassoon OH, Benyahia H. Evaluation of durability of composite materials applied to renewable marine energy: Case of ducted tidal turbine. Energy Reports, 2018;4 : 31-40.

[23] Singh PM, Choi, YD. Shape design and CFD analysis on a 1MW-class horizontal axis tidal current turbine blade. In IOP Conference Series: Materials Science and Engineering, 2013; 52( 5):052018.

[24] Nigam S, Bansal S, Nema T, Sharma, V, Singh, RK. . Design and Pitch Angle Optimisation of Horizontal Axis Hydrokinetic Turbine with Constant Tip Speed Ratio. In MATEC Web of Conferences ,2017; 95: 06004.

[25] Silva PA SF, Shinomiya LD, de Oliveira TF, Vaz JRP., Mesquita ALA, Junior ACPB. Analysis of cavitation for the optimized design of hydrokinetic turbines using BEM. Applied Energy, 2017;185:1281-1291.

[26] Nachtane M, Tarfaoui M, El Moumen A, Saifaoui D. Numerical investigation of damage progressive in composite tidal turbine for renewable marine energy. In Renewable and Sustainable Energy Conference (IRSEC), 2016: 559-563.

[27] Hassoon, O. H., Tarfaoui, M., El Moumen, A., Benyahia, H., \& Nachtane, M. (2017). Numerical evaluation of dynamic response for flexible composite structures under slamming impact for naval applications. Applied Composite Materials, 1-18.

[28] Tarfaoui M, Nachtane M, Khadimallah H, Saifaoui D. Simulation of mechanical behavior and damage of a large composite wind turbine blade under critical loads. Applied Composite Materials, 2018; 25(2):237-254.

[29] Goundar JN, Ahmed, MR, Lee YH. Numerical and experimental studies on hydrofoils for marine current turbines. Renewable energy, 2012; 42: 173-179.

[30] Wang D, Atlar M, Sampson R. An experimental investigation on cavitation, noise, and slipstream characteristics of ocean stream turbines. Proceedings of the Institution of Mechanical Engineers, Part A: Journal of Power and Energy, 2007;221(2): 219-231.

[31] Pennings P, Westerweel J, van Terwisga T. Cavitation tunnel analysis of radiated sound from the resonance of a propeller tip vortex cavity. International Journal of Multiphase Flow, 2016;83: 1-11.

[32] Batten, WMJ, Bahaj AS, Molland AF, Chaplin JR. Hydrodynamics of marine current turbines. Renewable energy, 2006; 31(2): 249-256. 
[33] Muratoglu A,Yuce MI. Performance Analysis of Hydrokinetic Turbine Blade Sections. Journal ISSN, 2015.

[34] Selig MS . Summary of low speed airfoil data (Vol. 1). SoarTech, 1995.

[35] Marten D, Pechlivanoglou G, Nayeri, CN, Paschereit CO. Integration of a WT Blade Design tool in XFOIL/XFLR5. In 10th German Wind Energy Conference (DEWEK 2010), Bremen, Germany, Nov (pp. 17-18).

[36] Wortmann FX. Visualization of transition. Journal of Fluid Mechanics, 1969; 38(3): 473-480.

[37] Wortmann FX. Progress in the design of low drag aerofoils. In Boundary Layer and Flow Control ,1961:748-770.

[38] Momeni H, Domagała M. CFD simulations of hydrofoils for tidal turbines. Czasopismo Techniczne, 2017; 10: 193-199.

[39] Shiu H, Johnson E, Barone M, Phillips R, Straka W, Fontaine A, Jonson M. A design of a hydrofoil family for current-driven marine-hydrokinetic turbines. In 2012 20th International Conference on Nuclear Engineering and the ASME 2012 Power Conference (pp. 839-847). American Society of Mechanical Engineers, 2012.

[40] Polagye BL, Cavagnaro RJ, Niblick AL. Micropower from tidal turbines. In ASME 2013 Fluids Engineering Division Summer Meeting (pp. V01BT12A006V01BT12A006). American Society of Mechanical Engineers.

[41] Singh PM, Choi YD. Shape design and numerical analysis on a $1 \mathrm{MW}$ tidal current turbine for the south-western coast of Korea. Renewable energy, 2014;68: 485-493.

[42] Yavuz T, Koç E, Kılkış B, Erol Ö, Balas C, Aydemir T. Performance analysis of the airfoil-slat arrangements for hydro and wind turbine applications. Renewable Energy, 2015; 74:414-421.

[43] Oller Aramayo SA, Nallim LG, Oller Martínez SH. The usability of the Selig S1223 profile airfoil as a high lift hydrofoil for hydrokinetic application. Journal of Applied Fluid Mechanics, 2016; 9(3): 537-542. 